\title{
Estudo comparativo das propriedades mecânicas dos aços SAE 1045 e SAE 1020, em diferentes condições metalúrgicas, através dos ensaios de tração unidirecional e flexão em três pontos
}

\author{
Comparative study of the mechanical properties \\ of SAE 1045 and SAE 1020 steels obtained from \\ unidirectional tensile and three-point bending tests
}

\author{
Felipe Govoni Bejo ${ }^{1}$, Celio Caminaga ${ }^{1}$, \\ Sílvio Aparecido Verdério Júnior ${ }^{1}$, Jhony Weliton Antonio ${ }^{1}$
}

\begin{abstract}
${ }^{1}$ Instituto Federal de Educação, Ciência e Tecnologia de São Paulo, IFSP Araraquara, Departamento da Indústria, Rua Doutor Aldo Benedito Pierri, 250, Jardim Paulo Freire, CEP 14804-296, Araraquara, SP, Brasil. E-mails: felipegbejo@hotmail.com; caminaga@ifsp.edu.br; silvioverderio@ifsp.edu.br; jhonywa88@yahoo.com.br.
\end{abstract}

\section{RESUMO}

Em aplicações de engenharia e da indústria, eixos mecânicos estão constantemente sujeitos a esforços de flexão e, consequentemente, solicitados por tensões normais de flexão. Essas tensões são calculadas pela "fórmula da flexão", que associa os esforços de flexão com os parâmetros geométricos do elemento solicitado. No entanto a aplicação dessa equação implica algumas restrições, que dificilmente são atendidas em situações reais. O presente trabalho avaliou e comparou a tensão de escoamento em tração e a tensão de flexão no limite da deformação elástica do material, obtidas através do ensaio de tração unidirecional e ensaio de flexão em três pontos, respectivamente. Para a obtenção da tensão de flexão no escoamento foi utilizada a "fórmula da flexão", de modo a comparar uma situação "real" com uma situação "ideal" e a partir da análise comparativa entre as duas situações observaram-se as diferenças entre os resultados. Os ensaios mecânicos foram realizados em corpos de prova em diferentes condições metalurgicas dos aços SAE 1020 e SAE 1045, sendo essas condições: laminado a quente, trefilado a frio, temperado e revenido, e normalizado. Ao final dos ensaios e da análise dos resultados, foi possivel observar com clareza as diferenças no comportamento dos materiais quando submetidos a diferentes tratamentos térmicos e processos de fabricação. Contudo, a análise comparativa da tensão de escoamento obtida pelo ensaio de tração unidirecional em relação a tensão de flexão no escoamento obtida no ensaio de flexão três pontos indicou que, dependendo do tratamento térmico ou processo de fabricação em que o material foi submetido, existem diferenças significativas entre as tensões comparadas; que podem levar ao superdimensionamento de projetos mecânicos. Palavras-chave: Propriedades mecânicas. Aço SAE 1020. Aço SAE 1045. Ensaio de tração. Ensaio de flexão.

\begin{abstract}
In engineering and industry applications, mechanical shafts are constantly subjected to bending stresses and, consequently, required by normal bending stresses. These stresses are calculated by the "flexure formula", which associates the bending efforts with the geometric parameters of the requested element. However, the application of this equation implies some restrictions, which are hardly met in real situations. The present work evaluated and compared the yield strength in traction and the maximum bending stress at the limit of the elastic deformation of the material, obtained through the unidirectional tensile test and bending test in three points, respectively. To obtain the maximum flexion tension was used the "flexure formula" to compare a "real" situation with an "ideal" situation, and from the comparative analysis between the two situations, the differences between the results were observed. The mechanical tests were carried out on specimens in different metallurgical conditions of SAE 1020 and SAE 1045 steels, being these conditions:
\end{abstract}


hot rolled, cold drawn, quenched and tempered, and normalized. At the end of the tests and the analysis of the results, it was possible to clearly observe the differences in the behavior of the materials when subjected to different heat treatments and manufacturing processes. However, the comparative analysis of the yield stress obtained by the unidirectional tensile test in relation to the maximum bending stress obtained in the three-point bending test indicated that, depending on the heat treatment or manufacturing process to which the material was subjected, there are significant differences between the stresses compared; that can lead to over-dimensioning of mechanical designs.

Keywords: Mechanical properties. SAE 1020 steel. SAE 1045 steel. Tensile test. Bending test.

\section{INTRODUÇÃO}

Na modelagem da flexão pura, para avaliação das tensões normais de flexão no dimensionamento de vigas ou eixos mecânicos, diversas considerações devem ser atendidas; que são, de acordo com SHIGLEY [1], NORTON [2], HIBBELER [3] e BEER et al. [4]:

- Viga carregada no plano de simetria longitudinal que contém os eixos dos apoios, o que não produz esforços cisalhantes de torção;

- Flexão Pura $(N=0, V=0, T=0$ e $M \neq 0)$ - onde $N$ é o esforço normal, $V$ é o esforço cortante, $T$ é o momento torçor e $M$ é o momento fletor;

- Seção transversal simétrica, de forma que o sistema de eixos utilizados coincide com a direção dos momentos de inércia principais;

- Material homogêneo, isotrópico e elástico-linear que obedece a Lei de Hooke;

- Hipótese de Navier-Bernoulli da Teoria de Euler-Bernoulli que enuncia que as seções planas e perpendiculares ao eixo da viga não deformado permanecem planas e perpendiculares ao eixo deformado. Hipótese válida para os casos de Flexão Pura e com boa aproximação para o caso geral de Flexão Composta para vigas esbeltas;

- Regime de pequenas deformações;

- As dimensões da viga devem proporcionar a falha por flexão e não esmagamento.

Em situações reais de engenharia tais restrições acabam não sendo atendidas integralmente, especialmente na utilização de materiais mais dúcteis [5] e mesmo durante o ensaio de flexão [6], em condições normalizadas e controladas, o caso de flexão pura raramente acaba sendo atendido. Dessa forma, objetivando reduzir os erros da aplicação da equação de flexão em condições reais e não plenamente atendidas pelas restrições de modelagem, aplicam-se coeficientes de segurança ao projeto, que amenizam as discrepâncias, mas não as eliminam totalmente.

A realização de ensaios mecânicos permite a obtenção de informações importantes sobre um material, com base em seu comportamento quando submetido a esforços externos [7]. Como exposto por ZHU et al. [8] o comportamento de materiais pode ser analisado com base em três aspectos: o comportamento de fratura; resistência; deformação linear e estricção da geometria. Diferentes condições metalúrgicas e a aplicação de tratamentos térmicos e termoquímicos modificam o comportamento de um material quando submetido a esforços, alterando sua resistência e ductilidade [9]. Tais processos de alteração microestrutural são amplamente utilizados para adaptar um material à diferentes aplicações.

Durante a seleção de um material para aplicação em um projeto é fundamental saber se as propriedades mecânicas do mesmo são adequadas, como seu limite de resistência a tração, módulo de elasticidade e tensão limite de proporcionalidade [10] e limite de escoamento de engenharia. Em um ensaio mecânico para a obtenção dessas propriedades, o número de amostras a ser ensaiada afeta diretamente a qualidade dos resultados; quanto maior for o número de corpos de prova ensaiados, melhor e mais realista é o resultado obtido [11].

O ensaio de tração unidirecional consiste na aplicação crescente de uma força unidirecional em um corpo de prova, de modo a alongá-lo em uma única direção até a sua ruptura; sendo possível extrair importantes informações sobre o material ensaiado, como a tensão de escoamento e o limite de resistência à tração. Como é observado por GARCIA [7] e SOUZA [12], é o tipo de ensaio mais aplicado no estudo de materiais metálicos, visto sua fácil aplicação e reprodutibilidade.

BEJO et al. [13], através da realização de ensaios de tração normatizados pela ABNT NBR ISO 6892-1 [14], exploraram as principais propriedades mecânicas dos aços SAE 1020 e SAE 1045 em diferentes condições metalúrgicas e validaram os resultados obtidos através de dados obtidos na literatura técnica e catálogos de fabricantes. WELITON ANTONIO et al. [15] estudaram os efeitos das condições metalúrgicas do processo de fabricação e dos tratamentos térmicos na dureza do aço SAE 1045 e também validaram os resultados obtidos através das informações em literatura técnica e catálogos de fabricantes.

O ensaio de flexão em três pontos, por sua vez, consiste em um corpo de prova biapoiado, no qual é 
aplicado uma força contínua e crescente em um ponto equidistante dos dois apoios, geralmente no centro da peça. Tem uma ampla gama de aplicações além da obtenção das tensões de um material $[16,17]$ e é mais aplicado em materiais frágeis, como materiais cerâmicos. Produz nos corpos de prova ensaiados dois esforços normais distintos, compressão na região que recebe o esforço diretamente e tração na região oposta que é "alongada" [18].

DE ALMEIDA e VERDÉRIO JÚNIOR [9] estudaram a influência dos tratamentos térmicos de têmpera e têmpera e revenimento nas propriedades mecânicas de flexão do aço SAE 1045. Discutiram as hipóteses de validação da equação de flexão e suas principais limitações, especialmente no trabalho com materiais mais dúcteis. Concluíram que a equação de flexão, em suas hipóteses de formulação, melhor emprega-se em materiais frágeis com região plástica reduzida ou unicamente na região elástica em materiais mais dúcteis.

O presente trabalho teve o objetivo de melhor compreender o comportamento e resposta dos aços SAE 1020 e SAE 1045, em diversas condições metalúrgicas, quando submetidos aos ensaios de tração unidirecional e flexão em três pontos. Também objetiva avaliar, comparar e estabelecer relações entre as principais propriedades mecânicas dos materiais ensaiados em tração e flexão.

\section{MATERIAIS E MÉTODOS}

Os materiais utilizados no trabalho foram os aços SAE 1020 e SAE 1045, divididos entre quatro barras de diâmetro 3/8" (9,53 mm) por $6000 \mathrm{~mm}$ de comprimento, sendo: uma barra do aço SAE 1020 (laminado a quente), uma barra do aço SAE 1020 (trefilado a frio), uma barra do aço SAE 1045 (laminado a quente) e uma barra do aço SAE 1045 (trefilado a frio). A composição química de cada barra, conforme certificado de qualidade do fornecedor, pode ser observada na Tabela 1. Esses valores encontram-se dentro das especificações nominais utilizadas em aplicações industriais e descritas na literatura técnica especializada [19-21].

Tabela 1: Composição Química (em percentual de massa) dos materiais de cada barra, conforme certificado de qualidade do fornecedor.

\begin{tabular}{l|c|c|c|c|c|c|c|c}
\hline MATERIAL & $\mathbf{C}$ & $\mathbf{M n}$ & $\mathbf{S}$ & $\mathbf{P}$ & $\mathbf{S i}$ & $\mathbf{C r}$ & $\mathbf{N i}$ & $\mathbf{C u}$ \\
\hline SAE 1045 trefilado a frio & 0,47 & 0,69 & 0,010 & 0,015 & 0,26 & 0,025 & 0,01 & 0,015 \\
\hline SAE 1045 laminado a quente & 0,47 & 0,65 & 0,014 & 0,013 & 0,20 & 0,080 & 0,03 & 0,070 \\
\hline SAE 1020 trefilado a frio & 0,19 & 0,37 & 0,008 & 0,010 & 0,08 & 0,010 & 0,01 & 0,000 \\
\hline SAE 1020 laminado a quente* & 0,14 & 0,50 & 0,022 & 0,030 & 0,14 & 0,030 & 0,00 & 0,020 \\
\hline
\end{tabular}

*Equivalente aos aços NBR 7007 grau NR-250 e ASTM A36.

As barras foram cortadas em partes menores de $200 \mathrm{~mm}$ de comprimento cada, caracterizando-se em corpos de prova (CP). Cada barra foi cortada em uma quantidade predeterminada de corpos de prova, conforme a Tabela 2, os quais foram utilizados para a realização de tratamentos térmicos e para os ensaios de tração e flexão.

Tabela 2: Quantidades de corpos de prova confeccionados para cada tipo de material.

\begin{tabular}{l|c|c}
\hline MATERIAL & QUANTIDADE DE CORPOS DE PROVA & CONDIÇÃO METALÚRGICA \\
\hline \multirow{2}{*}{ SAE 1045 trefilado a frio } & 10 & trefilado a frio \\
\cline { 2 - 3 } & 10 & temperado e revenido \\
\hline \multirow{2}{*}{ SAE 1045 laminado a quente } & 10 & laminado a quente \\
\cline { 2 - 3 } & 10 & normalizado \\
\hline SAE 1020 trefilado a frio & 10 & trefilado a frio \\
\hline SAE 1020 laminado a quente & 10 & laminado a quente \\
\hline
\end{tabular}

\subsection{Tratamentos Térmicos}

Uma quantidade de dez corpos de prova do aço SAE 1045 trefilado a frio foram submetidos aos tratamentos térmicos de têmpera e revenimento e outros dez corpos de prova do aço SAE 1045 laminado a quente foram submetidos ao tratamento térmico de normalização. Os parâmetros para os processos de tratamento térmico foram definidos conforme literatura técnica disponibilizada pela GGD Metais [19, 20].

Para a têmpera dos dez corpos de prova do material SAE 1045 trefilado a frio, manteve-se uma temperatura de austenitização de $890{ }^{\circ} \mathrm{C}$ durante 24 minutos (tempo de encharque), com posterior 
resfriamento em água. Em seguida, para a realização do revenimento, os corpos de prova já temperados foram levados a um segundo forno e mantidos a temperatura de $270{ }^{\circ} \mathrm{C}$ durante 20 minutos, com posterior resfriamento ao ar calmo.

Para a normalização dos dez corpos de prova do material SAE 1045 laminado a quente, manteve-se uma temperatura de austenitização de $890^{\circ} \mathrm{C}$ durante 24 minutos, com posterior resfriamento ao ar calmo.

Neste presente trabalho, cada amostra foi compostas por dez corpos de prova, dos quais cinco foram ensaiados em tração uniderecional e cinco em flexão três pontos. As amostras foram identificadas como: SAE 1045 trefilado a frio; SAE 1045 laminado a quente; SAE 1045 temperado e revenido; SAE 1045 normalizado; SAE 1020 trefilado a frio; SAE 1020 laminado a quente, caracterizando seis amostras diferentes.

\subsection{Realização dos Ensaios de Tração}

Para o ensaio de tração foram preparados cinco corpos de prova de cada tipo de cada amostra. Antes da realização dos ensaios os corpos de prova passaram por um processo de preparação, que consisitiu em marcar múltiplos comprimentos de calibração $\left(\mathrm{L}_{0}=50 \mathrm{~mm}\right)$ e o medição do diâmetro de calibração $\left(\mathrm{D}_{0}\right)$, para posteriormente serem submetidos ao ensaio propriamente dito. Os ensaios foram realizados em temperatura ambiente e todos os parâmetros empregados estão em conformidade com a norma técnica ABNT NBR ISO 6892-1 [14]. Também foi empregado um extensômetro de $50 \mathrm{~mm}$ para a medição da deformação das amostras durante os ensaios, conforme ilustrado na Figura 1. Para a medição dos diâmetros inicial e final foi utilizado um paquímetro com capacidade de $150 \mathrm{~mm}$ e com resolução de $0,05 \mathrm{~mm}$.

Os ensaios foram realizados em uma Máquina de Ensaios Universais EMIC DL 10000, capacidade de carga de $100 \mathrm{kN}$, com sistema de aquisição de dados através do Software Tesc versão 1.10. A velocidade de ensaio de $6 \mathrm{~mm} / \mathrm{min}$ e definiu-se o critério de finalização de ensaio como a ruptura do corpo de prova ou aplicação de carga superior a $95 \mathrm{KN}$, valor escolhido para preservar o equipamento e evitar danos a célula de carga.

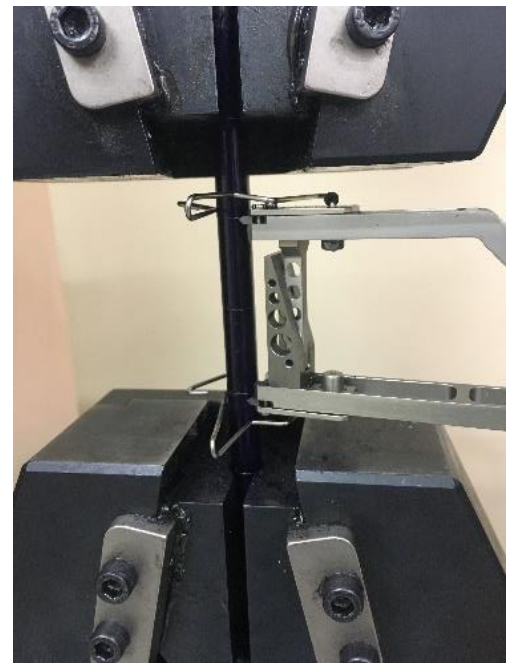

Figura 1: Arranjo experimental mostrando a fixação do corpo de prova nas garras e a montagem do extensômetro durante os ensaios de tração.

Para os ensaios de tração da amostra do aço SAE 1045 na condição metalúrgica temperado e revenido, foi necessário usinar os corpos de prova para redução do diâmetro da seção transversal (diâmetro de calibração) de 9,5 para $8 \mathrm{~mm}$, visto que a Máquina de Ensaios Universais não apresentava capacidade de carga suficiente para rompê-los. A Figura 2 apresenta as dimensões dos corpos de prova usinados. 


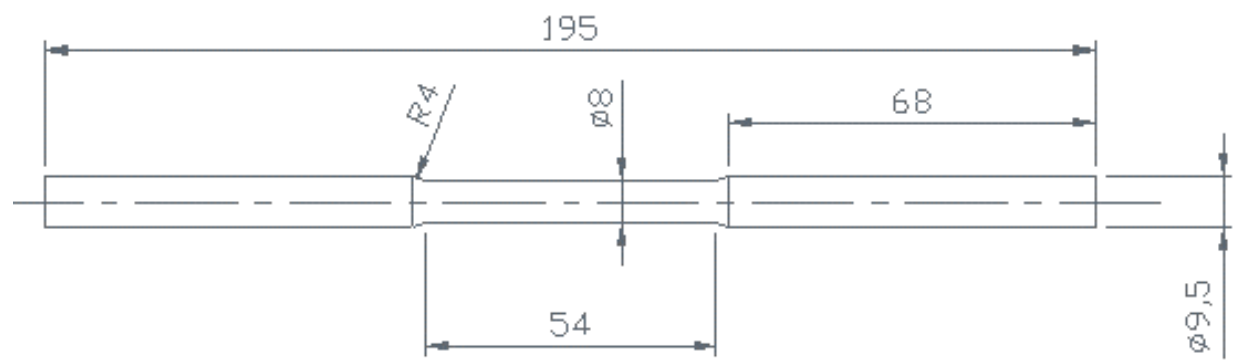

Figura 2: Desenho dos corpos de prova usinados da amostra de aço SAE 1045 trefilado a frio para posterior tratamento térmico de têmpera e revenimento.

\subsection{Realização dos Ensaios de Flexão}

De forma semelhante ao utilizado nos ensaios de tração, foram ensaiados cinco corpos de prova de cada amostra. Observando-se que, diferente do ensaio anterior, não se faz necessário a preparação prévia dos corpos de prova no ensaio de flexão.

Também utilizou-se a mesma Máquina de Ensaios Universais e o mesmo sistema de aquisição de dados, entretanto, foi usada uma célula de carga de $5 \mathrm{kN}$. A velocidade de ensaio foi de $5 \mathrm{~mm} / \mathrm{min}$ e definiu-se o critério de finalização de ensaio como o colapso de $2 \%$ (redução da força aplicada após atingir a carga máxima) ou ruptura do corpo de prova. A Figura 3 exemplifica o processo de realização do ensaio. $\mathrm{O}$ comprimento entre apoios (spam) empregado foi de $152 \mathrm{~mm}$, conforme recomendação da norma ABNT NBR 15668-2 [22], para uma razão entre spam e diâmetro do corpo de prova de 16:1, para diminuição da concentração de tensão nos apoios e no aplicador de carga.

Para a realização dos ensaios na amostra do aço SAE 1045 temperado e revenido, em face a maior resistência e menor capacidade de deformação, um ajuste de parâmetros mostrou-se necessário. Foi utilizado uma célula de carga de $30 \mathrm{kN}$, velocidade de ensaio de $2 \mathrm{~mm} / \mathrm{min}$ e manteve-se o critério de finalização de ensaio de colapso de $2 \%$, porém esperando-se a ruptura dos corpos de prova.

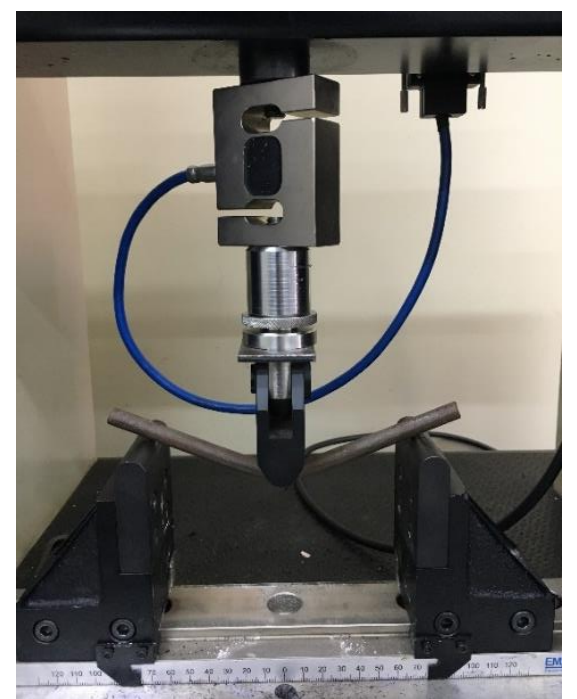

Figura 3: Arranjo experimental mostrando a realização do ensaio de flexão no aço SAE 1045 laminado a quente.

\subsection{Tratamento de Dados e Análise de Resultados}

Após a realização dos ensaios, os dados coletados através do Software Tesc versão 1.10 foram tratados, organizados e plotados com o auxílio do software Microsoft Excel 2010.

A obtenção da tensão de escoamento e limite de resistência à tração dos materiais ensaiados em tração, foram obtidos a partir da análise gráfica das curvas de tensão versus deformação. Para materiais que apresentaram patamar de escoamento vísivel, adotou-se a tensão de escoamento inferior presente nessa região. Contudo, para os materiais que não apresentam a patamar de escoamento, a obtenção da tensão escoamento foi realizada pelo critério da reta auxiliar (paralela à parte linear da região elástica), com uma pré-deformação 
de $0,2 \%$ e intersecção com a curva tensão versus deformação da amostra, conforme definido por ABNT NBR ISO 6892-1 [14] e SOUZA [12].

A tensão limite de flexão $\left(\sigma_{f}\right)$ representa a máxima tensão admitida pelo material antes do início da falha em flexão e, das hipóteses e formulações de SHIGLEY [1], NORTON [2], HIBBELER [3] e BEER et al. [4], para seções transversais circulares maciças, pode ser calculada através da equação (1).

$$
\sigma_{f}=\frac{32 . M}{\pi d^{3}}
$$

Onde:

$\sigma_{f}$ é a Tensão de Flexão, em MPa;

M é o Momento Fletor na seção crítica ensaida, em N.mm e calculado através da expressão $M=$ $(F . L) / 4$ - onde F é carga aplicada, em $\mathrm{N}$ e L é o spam, em mm;

d é o diâmetro da seção transversal resistente, em mm.

O momento fletor na seção crítica ensaiada foi obtido pelo critério da reta auxiliar (paralela à parte linear da região elástica), com uma pré-deformação de $0,2 \mathrm{~mm}$ de deflexão permanente e intersecção com a curva momento fletor versus deflexão dos corpos de prova ensaiados em flexão três pontos. Portanto, a tensão de flexão estudada neste trabalho, corresponde a uma tensão muito próxima ao limite de deformação elástica dos aços ensaiados em flexão, que chamamos de "tensão de flexão no escoamento" do material em flexão.

\section{RESULTADOS E DISCUSSÃO}

A partir do tratamento, análise e plotagem dos dados obtidos nos ensaios de tração realizados, foi construída a Tabela 3 e a Figura 4. A Tabela 3 apresenta os valores médios e o desvio padrão das propriedades mecânicas para cada amostra ensaiada. A Figura 4 apresenta as curvas tensão versus deformação representativas das amostras ensaiadas; diferentemente do procedimento realizado na confecção da Tabela 3 não foram utilizados os dados médios dos corpos de prova ensaiados por amostra, mas os resultados de corpo de prova representativo da amostra. Para a amostra do aço SAE 1045 temperado e revenido foi necessário descartar os resultados de dois corpos de prova, devido a ruptura ocorrer fora da região de calibração, portanto, foram considerados apenas três corpos de prova úteis.

Tabela 3: Valores médios das principais propriedades mecânicas em ensaio de tração unidirecional.

\begin{tabular}{c|c|c|c|c}
\hline AMOSTRA & $\begin{array}{c}\text { Tensão de } \\
\text { escoamento } \\
\pm \text { desvio padrão } \\
\mathbf{( M P a )}\end{array}$ & $\begin{array}{c}\text { Limite de Resis- } \\
\text { tência a Tração } \\
\pm \text { desvio padrão } \\
(\mathbf{M P a})\end{array}$ & $\begin{array}{c}\text { Alongamento } \\
\text { Percentual após } \\
\text { ruptura } \pm \text { desvio } \\
\text { padrão (\%) }\end{array}$ & $\begin{array}{c}\text { Estricção } \\
\pm \text { desvio padrão } \\
(\%)\end{array}$ \\
\hline SAE 1045 trefilado a frio & $771,8 \pm 15$ & $924,55 \pm 8$ & $11,38 \pm 1$ & $42,33 \pm 1$ \\
\hline SAE 1045 laminado a quente & $475,39 \pm 4$ & $677,15 \pm 3$ & $22,70 \pm 1$ & $51,19 \pm 4$ \\
\hline SAE 1045 temperado e revenido & $1477,33 \pm 18$ & $1549,72 \pm 90$ & - & - \\
\hline SAE 1045 normalizado & $395,18 \pm 7$ & $681,83 \pm 9$ & $23,90 \pm 4$ & $51,06 \pm 1$ \\
\hline SAE 1020 trefilado a frio & $564,8 \pm 6$ & $615,44 \pm 5$ & $11,78 \pm 1$ & $53,32 \pm 2$ \\
\hline SAE 1020 laminado a quente & $325,80 \pm 7$ & $466,22 \pm 8$ & $38,50 \pm 2$ & $67,65 \pm 1$ \\
\hline
\end{tabular}



Figura 4: Curva tensão versus deformação para os materiais em ensaio de tração. 
Analisando a Tabela 3 é possível observar que o aço SAE 1020 laminado a quente apresentou o maior alongamento percentual após a fratura e a maior estricção. Portanto, evidenciando os efeitos do menor percentual de carbono e principalmente do processo de fabricação aplicado ao mesmo. Esse material na condição metalúrgica em que se encontra, apresentou a maior ductilidade e consequentemente uma maior capacidade de deformação plástica, propriedade de grande interesse em processos de conformação plástica.

BEJO et al. [13] apresentam em maiores detalhes o processo de estricção nos aços 1020 e 1045 em diferentes condições metalúrgicas e resultados gráficos da influência da variação do diâmetro final com a evolução do comprimento dos corpos de prova em ensaios de tração. Esses resultados podem justificados através de análises químicas e microestruturais em relação ao percentual de carbono. Em condições semelhantes de resfriamento, as fases constituintes na microestrutura desses aços em temperatura ambiente podem ser muito diferentes, principalmente em condições industriais de resfriamento. Tem-se um aumento do microconstituinte perlítico, que é a mistura de duas fases (ferrita e cementita) no aço SAE 1045, na qual a cementita ou carbeto de ferro é uma fase rica em carbono [23]. A possibilidade de um maior percentual de perlita e consequentemente de cementita dentro dela, leva ao aumento da resistência mecânica e diminuição da ductilidade, por se tratar de uma fase muito dura e frágil [24]. Neste presente trabalho, essas diferenças foram analisadas do ponto de vista do limite de resitência a tração (caracterização da resistência mecânica) e do alongamento percentual e estricção (caracterização da ductilidade).

A Tabela 3 e a Figura 4 mostram o efeitos da condição metalúrgica (processo de fabricação e tratamento térmico) e do percentual de carbono nas principais propriedades das amostras ensaiados. Demonstra-se que o aumento do percentual de carbono contribui para a reduzir a ductilidade, capacidade de deformação linear e estricção da seção transversal e aumentar a resistência mecânica dos aços ensaiados. Isso pode ser claramente observado quando compara-se essas propriedades das amostras SAE 1020 e SAE 1045, ambas laminadas a quente.

Também observa-se que o processo de trefilação a frio, em comparação a laminação a quente, reduz a capacidade de deformação do material e aumenta a sua resistência mecânica, o que ocorre pelo fenômeno do encruamento do material presente em processos de deformação a frio. Entre os processos de tratamentos térmicos realizados, utilizou-se a têmpera e revenimento como maneira eficaz para aumentar a resistência mecânica do aço SAE 1045 trefilado a frio; contudo, reduziu-se muito a ductilidade, tornando-a praticamente nula. O material com micorestrutura martensítica (no estado temperado) torna-se muito resistente, porém a ductilidade é desprezível, quando comparado a outras microestruturas para o mesmo material. Os tratamentos térmicos de têmpera e posterior revenimento, resultam em uma microestrutura conhecida como martensita revenida. Essa microestrutura consiste de partículas de cementita extremamentes pequenas, dispersas de forma homogênia dentro de uma matriz ferrítica. O tratamento térmico de revenimento provoca um alívio das tensãoes internas do material provocas pelo tratamento de tempera, isso melhora a aplicabilidade do aço que passou por esse tratamento térmico [24]. O processo de normalização frequentemente utilizado para alívio de tensões em aços também utilizado neste trabalho não proporcionou alterações na ductilidade da amostra, entretanto, o limite de escoamento do material foi diminuído quando comparado ao aço SAE 1045 laminado a quente. Todas as observações e conclusões anteriores comprovam o expresso em literaturas e textos da área, também foram obtidas e comprovadas em [13, 15].

Procedeu-se o tratamento, análise e plotagem dos dados obtidos nos ensaios de flexão em três pontos realizados e através da aplicação da equação (1) obteve-se a Figura 5, que são as curvas tensão de flexão versus deflexão. Semelhante ao realizado no ensaio de tração, as curvas de flexão apresentadas na Figura 5 são de corpos de prova representativos das amostras ensaiadas. A Tabela 4 apresenta a média e o desvio padrão das tensões de flexão no escoamento das amostras em flexão. 


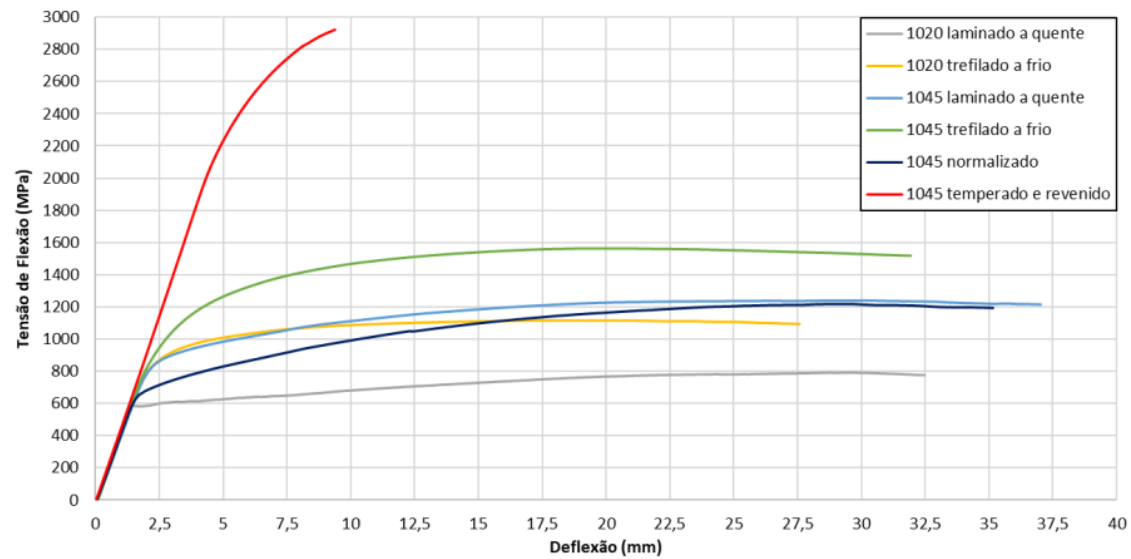

Figura 5: Curvas tensão de flexão versus deflexão para as amostras ensaiadas em flexão em três pontos.

Tabela 4: Valores médios das tensões de flexão no escoamento e seus respectivos desvios padrão para as amostras em ensaio de flexão em três pontos.

\begin{tabular}{l|c}
\hline AMOSTRA & Tensão de flexão no escoamento \pm desvio padrão (MPa) \\
\hline SAE 1045 trefilado a frio & $930,90 \pm 36$ \\
\hline SAE 1045 laminado a quente & $849,48 \pm 48$ \\
\hline SAE 1045 temperado e revenido & $2176,30 \pm 35$ \\
\hline SAE 1045 normalizado & $641,26 \pm 20$ \\
\hline SAE 1020 trefilado a frio & $799,38 \pm 20$ \\
\hline SAE 1020 laminado a quente & $560,74 \pm 25$ \\
\hline
\end{tabular}

Da análise das Figuras 4 e 5 podem ser observadas grandes semelhanças de comportamento dos materiais quando sujeitos a esforços de tração e flexão. Pode-se observar de forma qualitativa, a maior resistência à flexão nas amostras do aço com maior percentual de carbono em sua composição química ou nas amostras sujeitadas ao processo de deformação a frio ou ainda, a amostra submetida ao processo de têmpera e revenimento. Bem como, tem-se qualitativamente a menor resistência à flexão e maior capacidade de deformação de aços com menor percentual de carbono, laminados e/ou normalizados. Tais conclusões são análogas aos resultados obtidos em tração e possuem grandes semelhanças dos materiais em estudo nesses tipos de solicitação. Tais conclusões caminham no mesmo sentido e apresentam grandes semelhança de resultados com o estudo de DE ALMEIDA e VERDÉRIO JÚNIOR [9].

Comparando as tensões de escoamento em tração e as tensões de flexão no escoamento, respectivamente das Tabelas 3 e 4, construiu-se a Tabela 5; que apresenta a comparação das propriedades dos materiais ensaiados em tração e flexão. A última coluna da tabela apresenta de forma qualitativa o adimensional de comparação entre as duas tensões, denominado neste artigo de razão de tensão $\left(R_{t}\right)$ e calculado através da equação (2).

$$
R_{t}=\frac{\sigma_{f_{E}}}{\sigma_{E}}
$$

Onde:

$\sigma_{f_{E}}$ é a Tensão de flexão no escoamento obtida do ensaio de flexão em três pontos, em MPa; $\sigma_{E}$ é a Tensão de Escoamento obtida do ensaio de tração unidirecional, em MPa. 
Tabela 5: Comparação das tensões de escoamento média, tensão de flexão no escoamento média e razão de tensão.

\begin{tabular}{l|c|c|c}
\hline AMOSTRA & $\begin{array}{c}\text { Tensão de escoamento } \\
\pm \text { desvio padrão (MPa) }\end{array}$ & $\begin{array}{c}\text { Tensão de flexão no escoamen- } \\
\text { to } \pm \text { desvio padrão (MPa) }\end{array}$ & $\begin{array}{c}\text { Razão de tensão } \\
\text { (adimensional) }\end{array}$ \\
\hline SAE 1045 trefilado a frio & $771,8 \pm 15$ & $930,90 \pm 36$ & 1,21 \\
\hline SAE 1045 laminado a quente & $475,39 \pm 4$ & $849,48 \pm 48$ & 1,79 \\
\hline SAE 1045 temperado e revenido & $1477,33 \pm 18$ & $2176,30 \pm 35$ & 1,47 \\
\hline SAE 1045 normalizado & $395,18 \pm 7$ & $641,26 \pm 20$ & 1,62 \\
\hline SAE 1020 trefilado a frio & $564,8 \pm 6$ & $799,38 \pm 20$ & 1,41 \\
\hline SAE 1020 laminado a quente & $325,80 \pm 7$ & $560,74 \pm 25$ & 1,72 \\
\hline
\end{tabular}

Da análise da Tabela 5 observa-se uma grande discrepância entre os valores das tensões obtidas pelos ensaios de tração e de flexão. As tensões de flexão, considerando-se o critério de análise admitido, apresentam-se sempre superiores às tensões de escoamento em tração uniderecional, sendo $21 \%$ maior (Rt $=1,21)$, para o aço SAE 1045 trefliado a frio. Já para o aço SAE 1045 laminado a quente foi de $79 \%$ maior $(\mathrm{Rt}=1,79)$. Tal discrepância de resultados é sempre observada na literatura técnica, mas inexistem trabalhos que explorem e justifiquem tal relação.

SOUZA [12] estabelece uma relação semelhante ao comparar o módulo de ruptura em flexão, em $\mathrm{kgf} / \mathrm{mm}^{2}$, com o limite de resistência em tração, em $\mathrm{kgf} / \mathrm{mm}^{2}$ para o ferro fundido cinzento. Essa relação apresenta-se com o módulo de ruptura em flexão sendo aproximadamente o dobro da tensão limite de resistência à tração para o material ferro fundido, considerado de natureza frágil. No presente trabalho, o material SAE 1045 temperado e revenido estudado, que apresentou características de comportamento frágil, teve uma razão de tensão menor que o relatado por Souza [12], aproximadamente uma vez e meia na comparação das propriedades mecânicas estudas em flexão e em tração. Outro estudo similar foi feito por BALBO [25], que também observa as discrepâncias na resistência à tração indireta e na resistência à tração em flexão nos ensaios realizados em concreto, com a resistência à tração em flexão sempre maior que a resistência à tração indireta. O mesmo trabalho de BALBO [25] sugere que diferentes tamanhos e formatos de corpos de prova afetam o resultado do ensaio, podendo ser uma das justificativas das discrepâncias.

Para as outras amostras ensaiadas, que tiveram comportamento de natureza dúctil, observou-se uma grande variação dependendo da composição química e estado metalúrgico do material. Nota-se que os materiais trefilados a frio apresentaram a menor razão de tensão, respectivamente 1,21 e 1,41 para as amostras SAE 1045 e SAE 1020, ambas trefiladas a frio. A diferença das razões entre as amostras trefiladas a frio pode estar associada ao grau de deformação (encruamento) que a matéria-prima foi fornecida para o desenvolvimento deste estudo. Isso significa que dependendo do grau de encruamento do material, ou seja, com perda significativa da ductilidade, as tensões de escoamento e limite de resistência a tração tendem a se aproximarem.

Entretanto, para os materiais laminados a quente, a razão de tensão ficou em 1,79 e 1,72 para as amostras SAE 1045 e SAE 1020, respectivamente. Comparando com os resultados das amostras trefiladas a frio, cuja composição química são iguais, nota-se que as amostras que apresentaram maior ductilidade, também apresentaram maiores razões de tensão.

De SHIGLEY [1], NORTON [2], HIBBELER [3] e BEER et al. [4] tem-se que o processo de dimensionamento de peças sujeitas a flexão pura, considerando-se o critério da tensão admissível, considera como limite a tensão de escoamento, obtida do ensaio de tração unidirecional. Da análise da Tabela 5, desconsiderando-se as implicações das restrições da fórmula de flexão, suas limitações em materiais mais dúcteis e as influências dos coeficientes de segurança do projeto, tem-se que um material sujeito unicamente a flexão pura suportaria tensões superiores ao limite estabelecido da tensão de escoamento do ensaio de tração unidirecional. Dessa forma, o dimensionamento de peças sujeitas a flexão, considerando-se unicamente a tensão de escoamento em tração como critério de dimensionamento, implicaria em seções transversais maiores que o necessário; o que seria favorável a segurança do projeto, mas prejudicial as questões financeiras de custos, produção e competitividade do produto. Tal superdimensionamento poderia ser corrigido ou melhor investigado alterando-se o critério de dimensionamento e através da utilização de softwares de análise de tensões, comumente através do Método de Elementos Finitos ou de Elementos de Contorno.

Das discussões apresentadas com base na Tabela 5 e dos estudos de SOUZA [12] e BALBO [25], tornase necessário mais estudos para explorar a relação entre as propriedades dos materiais em tração e flexão e, avaliar as limitações da equação de flexão em outros tipos de solicitações em flexão, como em flexão quatro pontos e flexão engastada, bem como a variação da geometria do materiais (circular e retangular). Também 
pode-se verificar o comportamento em condições reais de engenharia e para materiais mais dúcteis a definição de critérios de dimensionamento a flexão pura, buscando reduzir os custos e preservar a segurança do projeto. Como proposta de estudo de caso para avaliação da última questão, os autores propõe o projeto (dimensionamento e fabricação) de um eixo submetido a flexão pura, utilizando-se como critério de falha a tensão de flexão no escoamento obtida no ensaio de flexão em três pontos, como tensão última de projeto. Com posterior realização de ensaios para avaliação do produto em flexão (ensaio de flexão convencional) e de fadiga (barreta rotativa com flexão reversa) para análises quanto a resistência, vida útil, segurança, confiabilidade e redução de custos do novo critério de dimensionamento estudado.

\section{CONCLUSÕES}

As propriedades mecânicas tanto dos materiais solicitados em tração quanto em flexão são influenciadas pela composição química, processo de fabricação e tratameno térmico. A discrepância de valores entre as tensões de escoamento em tração e tensões de flexão no escoamento para os materiais ensaiados pode ser claramente visualizada pela razão de tensão aplicada na análise das tensões.

A razão de tensão para os materiais frágeis pode variar dependendo do material como relatado na literatura. Contudo, para materiais de natureza dúctil que estejam encruados, a razão de tensão é fortemente diminuída. Por outro lado, os materiais com maior ductilidade apresentaram maiores razões de tensão e consequentemente maiores tensão de flexão no escoamento quando comparados (qualitativamente) aos materiais menos dúcteis. A amostra do aço SAE 1045 que passou pelo processo de normalização apresentou ductilidade semelhante ao mesmo aço no estado metalúrgico laminado a quente, entretanto, com razão de tensão qualitativamente menor.

A utilização da tensão de escoamento em tração no dimensionamento de estruturas sujeitas unicamente a flexão pura parece superdimensionar o projeto, favorecendo a segurança e prejudicando fatores econômicos; propondo-se como alternativa a utilização da tensão de flexão no escoamento do ensaio de flexão em três pontos para cálculo da tensão admissível de projeto no critério de dimensionamento. No entanto, mais estudos mostram-se necessários para melhor explorar a questão e avaliar alternativas de dimensionamento, especialmente através da utilização de softwares de análise de tensões e do Método de Elementos Finitos e também mais ensaios experimentais (flexão estática e em fadiga).

\section{AGRADECIMENTOS}

Ao Instituto Federal de Educação, Ciência e Tecnologia de São Paulo (IFSP), câmpus Araraquara, pelo fornecimento dos equipamentos, da força de trabalho e das condições de realização deste trabalho.

\section{BIBLIOGRAFIA}

[1] SHIGLEY, J. E., Elementos de Máquinas, v. 1, 3. ed., Rio de Janeiro: LTC, 1984.

[2] NORTON, R.L., Projeto de Máquinas: uma abordagem na integrada, 4. ed., Porto Alegre: Bookman, 2013.

[3] HIBBELER, R.C., Resistência dos Materiais, 7. ed., São Paulo: Pearson Prentice Hall, 2010.

[4] BEER, F.P. et al., Mecânica dos Materiais, 7. ed., Porto Alegre: McGraw-Hill Education, 2015.

[5] MIHAI, L.A., GORIELY, A., "How to characterize a nonlinear elastic material? A review on nonlinear constitutive parameters in isotropic finite elasticity", Proc. R. Soc. A 473: 20170607.

[6] CARVALHO, E.A., DUARTE, E.T.V., "Ensaios de flexão: uma revisão dos modelos matemáticos empregados na sua análise", In: Congresso brasileiro de engenharia e ciência dos materiais, São Paulo, 2000.

[7] GARCIA, A., Ensaios dos Materiais. LTC: Rio de Janeiro, 1. ed., 2000.

[8] ZHU, X.-K., JOYCE, J.A., "Review of fracture toughness (, , K, J, CTOD, CTOA) testing and standardization", Engineering Fracture Mechanics, v. 85, pp. 1-46, 2012.

[9] DE ALMEIDA, T.B., VERDÉRIO JÚNIOR, S.A., “Análise teórico experimental dos resultados obtidos no ensaio de flexão em três pontos para o aço SAE 1045 temperado com e sem revenimento", In: II Encontro de Iniciação Científica e Tecnológica - EnICT, Araraquara, outubro de 2017. ISSN: 2526-6772.

[10] HANNON, A., TIERNAN, P., “A review of planar biaxial tensile test systems for sheet metal”, Journal of Materials Processing Technology, v. 198, pp. 1-13, 2008.

[11] OLIVEIRA, J.E.F., "Estudo analítico da influência da correlação entre grandezas no cálculo da incerteza de medição da tensão de resistência mecânica”, revista Matéria, v. 19, n. 3, pp. 313-324, 2014.

[12] SOUZA, S. A. Ensaios mecânicos de materiais metálicos. 5. ed., São Paulo: Edgard Blucher, 1982.

[13] BEJO, F.G., VERDÉRIO JÚNIOR, S.A., CAMINAGA, C., "Estudo das propriedades mecânicas em tração dos aços SAE 1020 e SAE 1045 em diferentes condições metalúrgicas”, In: IV Encontro de Iniciação Científica e Tecnológica - EnICT, Araraquara, outubro de 2019. ISSN: 2526-6772. 
[14] ABNT NBR ISO 6892-1, Materiais metálicos - Ensaio de Tração Parte 1: Método de ensaio à temperatura ambiente, 70p., 2013.

[15] ANTONIO, J. W., JÚNIOR, S. A.V., CAMINAGA, C. "Estudo da dureza superficial do aço SAE 1045 em diferentes condições metalúrgicas", In: IV Encontro de Iniciação Científica e Tecnológica - EnICT, Araraquara, outubro de 2019. ISSN: 2526-6772.

[16] CAMPBELL, P. et al., "The use of the three point bend test to quantify the effects of the thermal pretreatment on rock strength", Minerals Engineering, v. 14, n. 8, pp. 901-904, 2001.

[17] Przybilla, C. et al., "Deriving the primary cumulative distribution of fracture stress for brittle materials from 3- and 4-point bending tests", Journal of the European Ceramic Society, n. 31, pp. 451-460, 2011.

[18] PODGORNIK, B., et al., "Analysis of factors influencing measurement accuracy of Al alloy tensile test results", Measurement science review, v. 16, n. 1, pp. 1-7, 2016.

[19] GGD Metals. 29 GGD - GGD Metals, AÇO 1045, https://www.ggdmetals.com.br/wpcontent/uploads/2015/07/A\%C3\%87O-1045.pdf, acessado em abril de 2019.

[20] GGD Metals. 28 GGD - GGD Metals, AÇO 1020, https://ggdmetals.com.br/wpcontent/uploads/2015/07/A\%C3\%87O-1020.pdf, acessado em julho de 2019.

[21] ABNT NBR 7007, Aço-carbono e aço microligado para barras e perfis laminados a quente para uso estrutural - Requisitos, 10 p., 2016.

[22] ABNT NBR ISO 15668-2, Implantes para ortopedia - Dispositivos de fixação intramedular Parte 2: Método de ensaio para flexão estática em quatro pontos de haste intramedular, 14 p., 2009.

[23] SILVA, A.L.V. C.; MEI, P.R.. Aços e ligas especiais. 2. ed., São Paulo: Blücher, 2006. 646 p.

[24] CALLISTER, William D.; RETHWISCH, David G. Ciência e engenharia de materiais: uma introdução. 5. ed., Rio de Janeiro: LTC, 2002. 589 p.

[25] BALBO, J.T., "Relações entre resistências à tração indireta e à tração na flexão em concretos secos e plásticos", Revista Ibracon de Estruturas e Materiais, v. 6, n. 6, pp. 854-874, dezembro de 2013.

\section{ORCID}

Felipe Govoni Bejo

Celio Caminaga

Sílvio Aparecido Verdério Júnior

Jhony Weliton Antonio https://orcid.org/0000-0002-8409-9890

https://orcid.org/0000-0002-8881-1363

https://orcid.org/0000-0001-9695-7197

https://orcid.org/0000-0002-9924-0711 